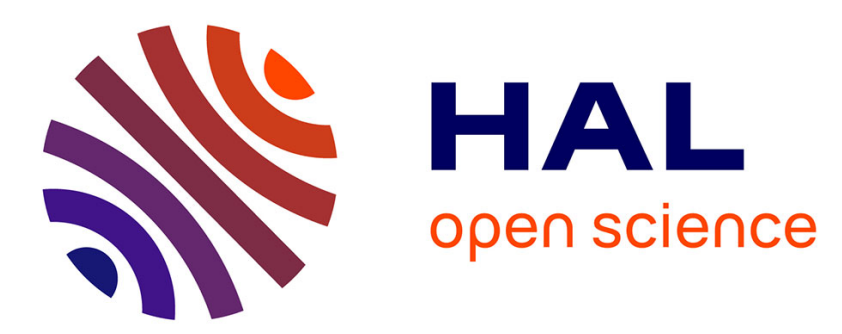

\title{
The Role of Non-social Benefits Related to Convenience: Towards an Enhanced Model of User's Self-disclosure in Social Networks
}

\author{
Tristan Thordsen, Matthias Murawski, Markus Bick
}

\section{- To cite this version:}

Tristan Thordsen, Matthias Murawski, Markus Bick. The Role of Non-social Benefits Related to Convenience: Towards an Enhanced Model of User's Self-disclosure in Social Networks. 15th Conference on e-Business, e-Services and e-Society (I3E), Sep 2016, Swansea, United Kingdom. pp.389-400, 10.1007/978-3-319-45234-0_35. hal-01702162

\section{HAL Id: hal-01702162 \\ https://hal.inria.fr/hal-01702162}

Submitted on 6 Feb 2018

HAL is a multi-disciplinary open access archive for the deposit and dissemination of scientific research documents, whether they are published or not. The documents may come from teaching and research institutions in France or abroad, or from public or private research centers.
L'archive ouverte pluridisciplinaire HAL, est destinée au dépôt et à la diffusion de documents scientifiques de niveau recherche, publiés ou non, émanant des établissements d'enseignement et de recherche français ou étrangers, des laboratoires publics ou privés.

\section{(c)(1)}

Distributed under a Creative Commons Attribution| 4.0 International License 


\title{
The role of non-social benefits related to convenience: towards an enhanced model of user`s self-disclosure in social networks
}

\author{
Tristan Thordsen, Matthias Murawski, and Markus Bick \\ ESCP Europe Business School Berlin, Berlin, Germany \\ tristan.thordsendedu.escpeurope.eu, \\ \{mmurawski, mbick\} @escpeurope.eu
}

\begin{abstract}
Despite the overwhelming and unabated popularity of social networks in the past years, the motivation behind an individual's registration to such platforms is still largely uncharted. Based on an in-depth review of leading Information Systems literature, this paper investigates which factors potentially influence individual's self-disclosure in social networks. The literature review reveals information privacy violation as the primary risk of online platform use. Regarding benefits, two categories are identified: social benefits, like reciprocity, relationship building and maintenance, or self-presentation as well as nonsocial benefits related to convenience, like personalization, entertainment, and safety and security. The later ones are mostly neglected in existing models. The main contribution of this paper consists of filling this gap by developing an enhanced research model of the user`s self-disclosure in social networks.
\end{abstract}

Keywords: Convenience, Privacy Concerns, Self-Disclosure, Social and NonSocial Benefits, Social Networks, Structured Literature Review

\section{Introduction}

Social networks enjoy impressive popularity. Facebook, as an example, counts approximately 1.55 Billion active users [1]. In 2015, 3.17 billion people in the world had access to the Internet. This means that close to $50 \%$ of all Internet users are Facebook members [2]. Generally, a social network is an online community where registered users present themselves on personal profiles and can interact with other users [3]. Other global social networks are for example Twitter, with around 320 million users [4], or Snapchat with approximately 200 million users [5]. Following the postulation of [6] that social networks should not be treated as one of a kind, we focus on the previously mentioned public social networks, which have a hedonistic purpose. Due to its size and importance, this group of social networks is already targeted by researchers such as [3] but requires further analysis [6].

Through the registration and subsequent creation of individual profiles, users reveal sensitive personal information. Publically the disclosure of personal data in social networks is debated controversially as it bears significant risks [7], [8]. The disclosed 
personal information can be a valuable asset to several agents in today's digitalized society. Companies for example have great interest in personal data as they can use it to gain insights and thus generate a technology-based competitive advantage [9]. Public authorities seek to understand dynamics of the society with the help of the data collected. However, criminals might also profit from the disclosed data [10]. Presenting sensible information about oneself in social networks can have severe tangible and intangible consequences such as identity theft, fraud, and misuse [8]. Despite these threats, social network users are willing and forthcoming with regards to sharing personal information with other users that may be complete strangers [11]. Literature in the field of self-disclosure coherently suggests that social benefits are key motivators behind personal information disclosure. Scholars base their argumentations on Social Exchange Theory [12] and its successors like the Privacy Calculus Model [13], which state that self-disclosure is an essential part of relationship building, ultimately resulting in an individual's social benefits and increased well-being.

Self-disclosure in social networks comprises the interaction of humans and technology and requires an interdisciplinary research approach [14]. Thus, this topic has caught the focus of the Information Systems (IS) community. Besides the focus on social aspects, recent IS literature dealing with behavior in social networks provides some hints on non-social benefits an individual can reap from self-disclosing in the networks. These additional benefits seem to be convenience-related [3]. However, they are neither clearly elaborated nor comprehensively presented in current research so far. This paper solely concentrates on motives of the individual. In doing so, we focus on enabling individuals to self-reflect and thus to create a practical additional value for the user. Aiming on developing an enhanced model of self-disclosure in social networks containing both social benefits and non-social benefits related to convenience, we formulate the following two research questions (RQ):

- RQ1: What are social benefits that affect individuals to disclose personal information in social networks?

- RQ2: What are non-social benefits related to convenience that affect individuals to disclose personal information in social networks?

This paper contributes on a theoretical level by building the foundation for a revised research model stating the factors that affect users to disclose personal information in social networks. Based on that, hypotheses for future empirical research are formulated. The remainder of this paper is organized as follows. First, the literature review is presented. Results are discussed subsequently leading to the revised model and respective hypotheses. The paper ends with a conclusion.

\section{$2 \quad$ Literature review}

Our method of choice is a structured literature review that analyzes and summarizes findings from available papers, while identifying research gaps and giving direction for future research [15]. The literature review objectively identifies different points of view for specific keywords or phrases and clusters a heterogeneous collection of literature available [16]. 
Recent studies discuss the cross-functional and cross-disciplinary nature of research activities concerning social networks and emphasize the central role for IS scholars, given the longstanding tradition of the IS field dealing with such questions [17]. Consequently, our focus lies on IS literature. Thus, publications from other related disciplines like law and psychology are excluded in this paper. Our objective is to work out to what extend the academic discipline of IS has engaged in exploring and analyzing the phenomenon of user's self-disclosure in social networks until today. Therefore, this work is based on a discussion of renowned IS literature published between 2008 and October 2015. This timeframe appears to be especially relevant as starting from 2008 a sharp increase of social network user numbers around the world is perceivable [1]. For identifying relevant IS literature, the VHB Jourqual 3 ranking of 2015 for "Wirtschaftsinformatik" (IS) published by the German Academic Association for Business Research is taken as basis [18]. Although a multitude of different journal rankings exists [19], the VHB Jourqual 3 is chosen because of both its topical character and scope regarding IS journals. For this literature review, only academic IS journals with a VHB Jourqual rating of "leading scientific journal in business administration and its subdomains, Category A" and "outstanding, worldwide leading scientific journal in business administration and its subdomains, Category A+" are taken into consideration for research [20]. Moreover, Business \& Information Systems Engineering, a leading European journal is included to provide additional geographical and thematic diversity. Last, in order to gain a meta-perspective on the phenomenon of online self-disclosure, publications of the A+ Business Administration journal Science are analyzed based on the given timeframe and parameters. In total, 13 academic journals have been identified for the literature review. This choice of literature fulfills a number of important criteria. The chosen journals all enjoy high acceptance and relevance in their fields and represent topical, as well as geographical diversity. As claimed by [21], major contributions in IS are most likely to be found in the leading journals. Finally, our journal selection covers the "Senior Scholars' Basket of Journals" ("SenS8" in list below) that comprises the eight "top IS journals" [22]. This set of journals is commonly used when analyzing the IS field [23]. The complete list of the 13 selected journals in alphabetical order is Business \& Information Systems Engineering (Jourqual 3 rating: B), European Journal of Information Systems (A, SenS8), Information Systems Journal (A, SenS8), Information Systems Research (A+, SenS8), INFORMS Journal on Computing (A), Journal of Information Technology (A, SenS8), Journal of Management Information Systems (A, SenS8), Journal of Strategic Information Systems (A, SenS8), Journal of the Association for Information Systems (A, SenS8), Management Information Systems Quarterly (A+, SenS8), Mathematical Programming (A), Science (A+), and SIAM Journal on Scientific Computing (A).

Search strings used for identifying topic related literature are: Internet, data, Social Media, Social Network, privacy, disclosure. These keywords have been obtained by a first explorative search in three of the journals, namely Information Systems Research, MIS Quarterly, and Journal of Management Information Systems. Within these journals and the given timeframe, six relevant articles were identified. Based on common subject terms of these articles the above keywords for further literature search were generated. In order to lay a wide focus and to increase accuracy, these keywords are 
applied one after the other during the research process. The search resulted in 26 articles which are subject to further analysis. Given the diversity and nature of the publications at hand, directed content analysis is chosen as analyzing tool for the literature review. This qualitative research method provides knowledge and understanding of the subject under study by coding or categorizing information and identifying key topics and patterns [24]. This method can also be interpreted as a deductive category application since it clusters qualitative content according to key theoretical concepts while identifying relationships and networks in the literature pool [25].

As a result of the literature review, three main foci of the papers at hand have been identified: self-disclosure, data analytics, and privacy. Seven articles are aggregated under the topic self-disclosure. The topic of data analytics accounts for nine articles. The largest category privacy comprises the remaining ten papers. It is important to note that topic foci of the literature tend to vary in accordance with the respective year of publication. As concepts determine the organizing framework of a high-quality literature review, it is important to detect the most prominent concepts used in the literature at hand [21]. Social Exchange Theory, Privacy Calculus and Privacy Concerns appear most frequently in the articles. It has to be pointed out that the articles [3], [11], [26], and [27] refer to all of the three respective concepts. They use Social Exchange Theory as basis for their research. The concepts of Privacy Calculus and Privacy Concerns are then employed as an extension of Social Exchange Theory in a social network context, meaning that a certain interrelatedness between the three theories can be observed. The majority of articles thus analyzes the factors behind selfdisclosure from a social sciences point of view. However, while often being unstructured, certain non-social benefits are mentioned, as well.

Referring to our research questions, Figure 1 illustrates the scope of factors that affect individuals to self-disclose in social networks presented in the literature at hand. It comprises the main findings of our literature review related to both social motives and non-social benefits that affect individuals to self-disclose in social networks.

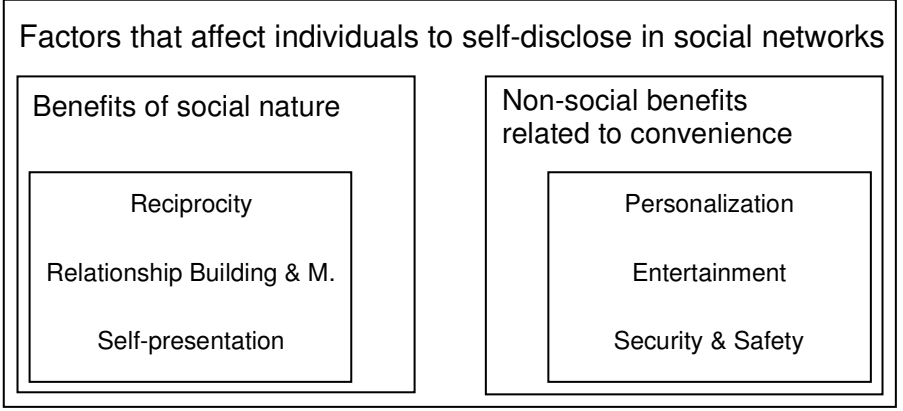

Fig. 1. Social and non-social benefits that affect individuals to self-disclose in social networks 


\section{Discussion}

This chapter discusses our findings while giving answers to our research questions. Section 3.1 focuses on the social benefits that are considered to have an influence on user`s self-disclosure in social networks. Non-social benefits related to convenience, which are often neglected in recently published models, are elaborated in section 3.2 before mediating factors are shortly discussed (section 3.3). Our revised model is presented in section 3.4.

\subsection{Social benefits}

The majority of the analyzed literature has identified reciprocity, relationship building and maintenance, and self-presentation to be the major benefits that individuals can reap from online self-disclosure (cf. Figure 1). These dimensions are interrelated and overlapping. However, they are the answer to RQ1. Compared to the non-social benefits related to convenience, the social benefits are presented rather briefly, which is caused by the general agreement upon these aspects. However, their discussion is required due to the aim of developing a comprehensive model.

Reciprocity. Often also referred to as reciprocation, reciprocity can be seen as quid pro quo communication, a fair exchange of information between two individuals, synonymous with a "you tell me and I'll tell you" orientation [3]. Reciprocity is a signal between the communicating parties that they are willing to agree to a certain degree of vulnerability through the disclosure of personal information to advance their relationship [26]. This signal of mutual acknowledgement and appreciation of the relationship is perceived as a very positive message by the interacting parties. It fosters intimacy and social connection or bonding. Reciprocity lays the basis for any interpersonal relationship and is the primary benefit of self-disclosure [28]. The phenomenon of reciprocity can be seen as a driver for the intensification of relationships [3]. It leads to a greater willingness to provide further personal information, therefore increasing a person's vulnerability. However, individuals perceive an effect of increasing intimacy through the advancement of the relationship which is highly rewarding and "maximizes the benefit of the interactions" [26, p. 170].

Relationship Building and Maintenance. In social networks, it is possible to foster existing relationships and to gain new social contacts, which leads to the positive feeling of social connection and bonding [11]. A newly gained network of contacts and relations can then be easily maintained through the social network services [3]. One can interact conveniently and efficiently with a large number of friends. In [29] this argument is supported based on a Delphi study classifying user's overall active behavior on social networks. In this context, it is essential to point out that only a small fraction of about $10 \%$ of users is seen as continuously active in social networks. Relationship building and relationship maintenance was defined part of the active behavior of over $85 \%$ of all users in the Delphi study. 
Self-presentation. Studies in the field of social networks confirm that benefits from self-presentation positively influence individuals to use social networks [3]. Driven by the desire for self-presentation, social network users disclose private information. Due to the asynchronous and selective forms of communication in social networks, users have the possibility to form an image of themselves that they wish to convey to others. Thus, self-presenting users only disclose information that seems desirable to them. This phenomenon is also called self-enhancement [27]. As described in [30], users engage in impression management when designing their social network profiles. By doing so, they seek to influence the impressions others hold about them. Such action helps the individual to feel comfort. Another kind of self-presentation in social networks can be the use of the service as online Curriculum Vitae [10].

\subsection{Non-social benefits related to convenience}

Scholars of the literature pool directly and indirectly point out further positive factors that users can profit from when registering to a social network. The defined benefits all link to the "one click away" approach that refers to an increased ease of access to a certain goal [3]. In e-commerce, convenience is described as the perceived economization of time and effort for an individual in acquiring a certain benefit [31]. Assuming that individuals try to maximize their subjective utility while minimizing their costs, users will choose the more convenient, thus easier and/or faster way to achieve an equally desirable goal. Convenience has a significant impact on an individual's behavior and decision making [32]. In [3] the concept of convenience is applied to social networks. The authors show that social networks provide relatively high convenience when building social relationships. Our findings show that social networks offer a great variety of convenience for the user in other fields, as well. Convenience can be seen as a core category of factors that is connected with a number of central categories [33]. It is essential to point out that due to the broad definition of convenience, the central categories we have identified are overlapping to a certain degree and are thus not perfectly distinct. Formulating an answer on RQ2, we have identified convenience through personalization, convenience in entertainment, and convenience in security and safety as the central categories. It must be noted that convenience through personalization is the most prominent non-social category in the literature we analyzed.

Convenience through Personalization. Providers of social networks collect and analyze all personal data that is disclosed by its members on the platforms [7]. Due to the rising popularity of social networks, users release an unprecedented, massive and increasing stream of data that requires processing. The overwhelming amount of data accumulated through a great number of new data-generating sources, including social networks, has led to a new phenomenon in the fields of business intelligence and analytics [9]. This phenomenon is widely known as big data or big data analytics. These terms stand for "data sets and analytical techniques in applications that are so large and complex that they require advanced and unique data storage, management, analysis and visualization technologies" [34, p. 1166]. The aim of data analytics is to iden- 
tify and extract actionable insights from the available data [35]. Personalization is significantly enabled by big data. However, an increased ability of customization is only one of the many outcomes of big data analytics. Making use of such techniques, social network providers process the detailed disclosed personal data to reveal preferences, tastes and other specific information that can give insights on an individual's personality [36]. Based on the identified set of preferences, social network providers propose tailored content that fits the user's profile. Furthermore, the appearance of the individual's profile start page, as well as communication of the providers with the member is designed according to the user's personality. The adaption of a service or product to a person's preferences is called personalization [37]. Theory suggests that "users favor personalized communication and content that matches their taste" [38, $p$. 132]. In social networks, features and appearance can be personalized in real time through data automation [9]. In addition to the individualized content, data gathered by social network providers enables firms to target individual customers with tailored ads and products. In [39] personalized products are identified as an important economic benefit for the user, while in [38] a similar view emphasizing an increased customer satisfaction due to customization is presented. Customer relationship management becomes more efficient and effective through the personalized communication in social networks [40]. The user saves time and effort due to the customization of content and communication within social networks. The data gathered in social networks also enables tailored communication and product recommendations to the user outside of the online networks [38]. In addition, social network users have the opportunity to log into other websites using their social network credentials and can thus automatically create new accounts, provide address information and preferences. The content of those websites is then often customized for the user as well [37]. This uncomplicated data transfer and ease of access to other websites results in considerable economization of time and friction costs for the social network user, even outside the networks. According to [41], these benefits can animate consumers to disclose personal information. In [37] it is shown that personalization comes at the price of an increased privacy trade-off. This is due to the augmented analysis and trade of personal data utilized to customize content for users both in and outside social networks.

Convenience in Entertainment. Studies revealed social networks as "purely hedonic platforms" where enjoyment is a stronger predictor of use and participation than perceived usefulness [42, p. 1221]. In 2009, according to Facebook, "more than 70 percent of all users engaged with platform applications every month" [3, p. 116]. All of these platform applications are accessible through a single social network site. Therefore, the user economizes considerable time and effort in accessing the desired applications and most notably in changing between them, if necessary. In addition, these applications are well integrated into the platforms and the interaction and trading of virtual goods with other users is facilitated. In [27] and [3] the positive influence of enjoyment in social applications within social networks on users' self-disclosure is outlined. The authors focus solely on applications that enable the user to reveal their preferences regarding hobbies and tastes. Nevertheless, it is important to consider the availability of other enjoyment-related resources such as short videos, music, news- 
paper articles and further entertaining content that does not provide social benefits to the user, as well. $90 \%$ of social network members are qualified as lurkers, thus passive users, according to $[29$, p. 215]. These users predominantly engage in the consumption of information and entertainment. This form of entertainment and the convenient access to a great number of diverse applications and content constitutes an important additional benefit to social network users.

Convenience in Security and Safety. To date, this potential benefit hasn't found much attention in the journals' publications. Nevertheless, in order to provide an adequate and comprehensive analysis of all selected articles, the identified additional benefit to a social network user is also presented here. Detailed private information can contribute to safety and security. Similar to personalization, security and safety are strengthened by big data analytics. An individual's disclosure of personal information in social networks may contribute to public safety and security, and ultimately even to the wellbeing of the user himself. In many countries, social network users often provide their personal information automatically to intelligence, public safety, and security agencies when disclosing them in the networks [34]. Without further efforts, social network users thus conduce to the fight against terrorism and crime that may ultimately affect them personally. According to $[9$, p. 7], "the precise capture of individual online behavior and surrounding events" has amongst others a considerable impact on public safety. Given the convenient way in achieving this benefit, an additional value to the social network user related to convenience can be perceived.

\subsection{Mediators: Trust and Social Pressure}

Besides the previously discussed constructs that represent the core findings of many articles, the literature pool also suggests that trust and social pressure are potential mediators affecting the dynamics of an individual's behavior and perception of privacy risk in social networks [7]. Trust in the context of this article can be defined as a person's belief that the other party of interaction possesses "characteristics that inhibit it from engaging in opportunistic behavior" [3, p. 116]. From a Social Exchange Theory perspective, a certain amount of trust is a prerequisite for individuals to experience reciprocation and to build relationships. It mitigates the subjective risk perceptions of disclosing personal information to the other party and thus enables social exchange in general [28]. Individuals, who perceive their relational counterpart as to be trustworthy, tend to disclose more personal of themselves to the other party. This holds true in online communities as well [7]. Likewise social pressure or peer pressure can impact individual self-disclosure in online communities [3]. In order to be part of a group and thus to reap the resulting social benefits may encourage individuals to contribute and disclose personal information in social networks [26]. 


\subsection{Towards an enhanced model of user`s self-disclosure in social networks}

Based on the structure of the conceptual models of [3], [28], and further insights gained through the literature review, the following conceptual model is developed (Figure 2). It illustrates factors that potentially influence an individual to disclose personal information in social networks. Social benefits hypothetically constitute a major factor influencing users to self-disclose in the online communities. Simultaneously, additional non-social benefits related to convenience are expected to have a considerable impact on the user's motivation to self-disclose. It is noteworthy that in contrast to existing concepts, the presented model examines benefits of self-disclosure in social networks from both the social perspective and the non-social conveniencerelated perspective. As opposed to the models that provide the structural basis, privacy concerns is chosen as a construct instead of perceived privacy risk. In [3] and [28] perceived privacy risk is utilized as a privacy proxy built on complementary constructs such as trust in social network providers and members. Privacy concerns is a more recent concept and finds high acceptance in the IS community. Moreover, it is an adequate tool for measuring an individual's worries and beliefs regarding privacy [11]. Thus, in this context, privacy concerns are a more suitable privacy proxy to apply in this research model. Trust and social pressure are mediators influencing the relationships between privacy concerns and self-disclosure and social benefits and self-disclosure, respectively.

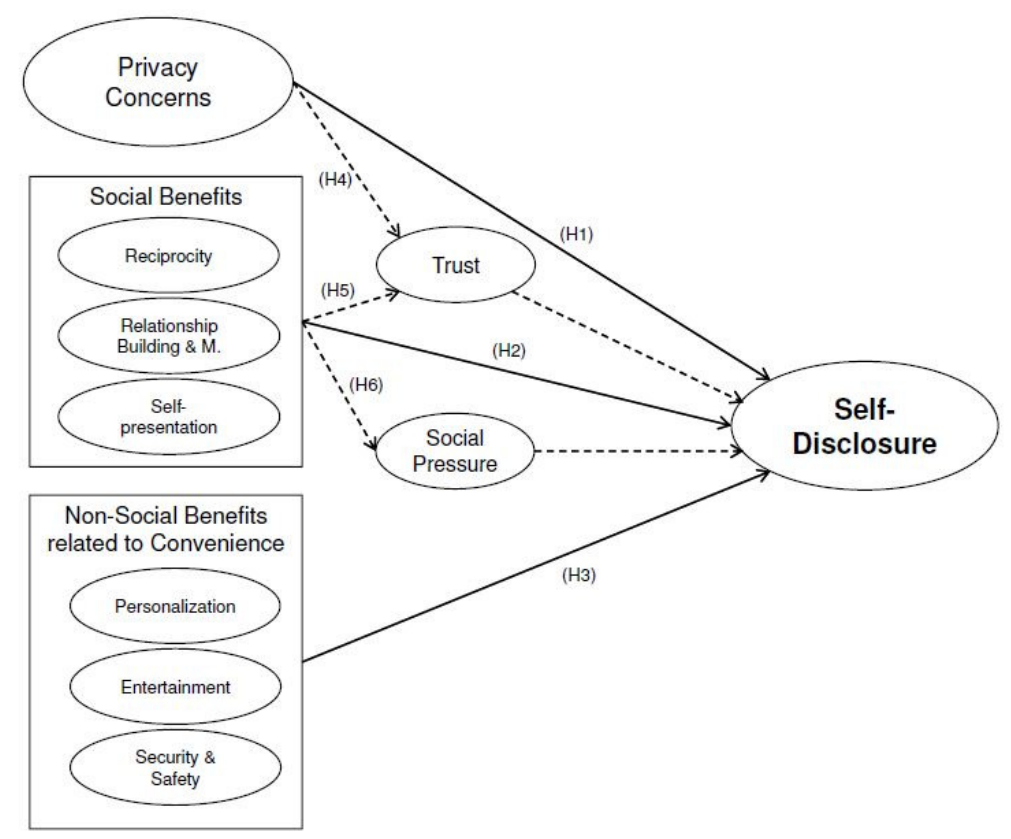

Fig. 2. Research model of user`s self-disclosure in social networks, based on the literature review and structured according to [3, Fig. 1], [28, Fig. 1] 
Based on our model, the following hypotheses can be derived:

- H1: Privacy concerns have a negative impact on self-disclosure in social networks

- H2: Social benefits have a positive impact on self-disclosure in social networks

- H3: Non-social benefits related to convenience have a positive impact on selfdisclosure in social networks

- H4: Trust acts as a mediator for the relationship between privacy concerns and self-disclosure

- H5: Trust acts as a mediator for the relationship between social benefits and selfdisclosure

- H6: Social pressure acts as a mediator for the relationship between social benefits and self-disclosure

\section{Conclusion}

Given the high relevance of research about user's self-disclosure in social networks, this paper contributes by highlighting non-social benefits that are related to convenience as an additional motivational factor for users. Combined with already established social benefits and the concept of privacy concerns, a revised research model was developed. This model enables us to derive six hypotheses, paving the way for future research opportunities. Until now, the theoretical model lacks empirical analysis. Similar empirical studies primarily examine sample groups that consist entirely of students. Future research on the motives and behavior of individuals in social networks based on a broader diversity of sample populations, e.g., to include older or working individuals, is a relevant objective. Thereby, a more complete picture of an individual's motives in social network use can be obtained. Studies largely concentrate on the Facebook online community in their observation. A thorough analysis of self-disclosure in other social networks would therefore be desirable. A limitation of our paper is that apart from the Science magazine, only leading journals in the field of IS were reviewed as we assume those to include the major contributions as well as the highest quality publications [21]. Lower-ranked journals and conference proceedings were thus not part of the literature pool. Moreover, research areas such as legal aspects of privacy or literature on behavioral science were excluded due to the IS focus of the literature review. An examination of these areas is likely to provide useful additional information on the topics and provide exciting opportunities for further research.

\section{References}

1. Statista: Facebook: number of monthly active users worldwide 2008-2015, http://www.statista.com/statistics/264810/number-of-monthly-active-facebook-usersworldwide/.

2. Statista: Number of worldwide \{Internet\} users from 2000 to 2015 (in millions), http://www.statista.com/statistics/273018/number-of-internet-users-worldwide/. 
3. Krasnova, H., Spiekermann, S., Koroleva, K., Hildebrand, T.: ONLINE SOCIAL NETWORKS: WHY WE DISCLOSE. J. Inf. Technol. Vol. 25, N, 109-125 (2010).

4. Twitter Inc.: About Twitter, https://about.twitter.com/company.

5. Statista: Global social networks by users 2015, http://www.statista.com/statistics/272014/global-social-networks-ranked-by-number-ofusers/.

6. Richter, D., Riemer, K., vom Brocke, J., Große Böckmann, S.: Internet Social Networking - Distinguishing the Phenomenon from its Manifestations. In: Proceedings of 17th European Conference on Information Systems, Verona (2009).

7. Gerlach, J., Widjaja, T., Buxmann, P.: Handle with care: How online social network providers' privacy policies impact users' information sharing behavior. J. Strateg. Inf. Syst. 24, 33-43 (2015).

8. Acquisti, A., Brandimarte, L., Loewenstein, G.: Privacy and human behavior in the age of information. Science (80-. ). $509 \mathrm{ff}$ (2015).

9. Goes, P.B.: Big Data and IS Research. Science (80-. ). 38, (2014).

10. Tow, W.N.H., Venable, J.R., Dell, P.: Understanding Information Disclosure Behaviour in Australian Facebook Users. J. Inf. Technol. 1019-1028 (2010).

11. Jiang, Z.J., Heng, C.S., Choi, B.C.F.: Privacy Concerns and Privacy-Protective Behavior in Synchronous Online Social Interactions. Inf. Syst. Res. (2013).

12. Thibaut, J., Kelley, H.: The Social Psychology of Groups. John Wiley, New York (1959).

13. Ryschka, S.: Location-Based Services from a User's Perspective Benefits and Risks, http://opus.escpeurope.de/opus4/files/19/Dissertation_Stephanie_Ryschka_2015_online.pd f, (2015).

14. Martensen, M., Börgmann, K., Bick, M.: The Impact of Social Networking Sites on the Employer-Employee Relationship. In: Proceedings of the 24th Bled eConference. eFuture: Creating Solutions for the Individual, Organisations and Society, Bled, Slovenia, 12.15.06.2011. (2011).

15. Rowe, F.: What a literature review is not - diversity, boundaries and recommendations. Eur. J. Inf. Syst. 3, p. 240-250 (2014).

16. Boote, D.N., Beile, P.: Scholars before researchers: On the centrality of the dissertation literature review in research preparation. Educ. Res. 6, 3-15 (2005).

17. Aral, S., Dellarocas, C., Godes, D.: Social media and business transformation: A Framework for research. Inf. Syst. Res. 24, 3-13 (2013).

18. VHB: Teilrating Wirtschaftsinformatik, http://vhbonline.org/service/jourqual/vhbjourqual-3/teilrating-wi/.

19. Harzing, A.-W.: Journal Quality List, http://www.harzing.com/resources/journal-qualitylist.

20. VHB: VHB Jourqual 3 Rating, http://vhbonline.org/en/service/jourqual/.

21. Webster, J., Watson, R.T.: ANALYZING THE PAST TO PREPARE FOR THE FUTURE: WRITING A LITERATURE REVIEW. MIS Q. 26, pp. xiii-xxiii (2002).

22. AIS: Senior Scholars' Basket of Journals, https://aisnet.org/?SeniorScholarBasket.

23. Sørensen, C., Landau, J.S.: Academic agility in digital innovation research. J. Strateg. Inf. Syst. Volume 24, 158-170 (2015).

24. Downe-Wamboldt, B.: Content analysis- Method, applications, and issues. Health Care Women Int. 13, 313-321 (1992).

25. Hsieh, H., Shannon, S.E.: Qualitative Health Research. 15, 1277-1288 (2005).

26. Lowry, P.B., Cao, J., Everard, A.: Privacy Concerns Versus Desire for Interpersonal Awareness in Driving the Use of Self-Disclosure Technologies: The Case of Instant Messaging in Two Cultures. J. Manag. Inf. Syst. 27, 163-200 (2011). 
27. Krasnova, H., Veltri, F.N., Günther, P.O.: Self-disclosure and Privacy Calculus on Social Networking Sites: The Role of Culture. Bus. Inf. Syst. Eng. 127-135 (2012).

28. Posey, C., Lowry, P.B., Roberts, T.L., Ellis, T.S.: Proposing the online community selfdisclosure model : the case of working professionals in France and the UK who use online communities. Eur. J. Inf. Syst. 19, 181-195 (2010).

29. Chen, A., Lu, Y., Chau, P.Y.K., Gupta, S.: Classifying, Measuring, and Predicting Users , Overall Active Behavior on Social Networking Sites. J. Manag. Inf. Syst. 31, 213-253 (2014).

30. Richter, D., Riemer, P.D.K., vom Brocke, P.D.J.: Internet Social Networking Research State of the Art and Implications for Enterprise 2.0. Bus. Inf. Syst. Eng. 89ff (2011).

31. Izquierdo-Yusta, A., Schultz, R.J.: Understanding the Effect of Internet Convenience on Intention to Purchase via the Internet. J. Mark. Dev. Compet. 5, (2011).

32. Rao, H.K.: ON RISK , CONVENIENCE , AND INTERNET SHOPPING. Commun. ACM. 43, (2000).

33. Kacen, L., Rabinovich, M.: QUALITATIVE CODING METHODOLOGY. Psychoanal. Psychol. 30, 210-231 (2013).

34. Chen, H., Storey, V.C., Chiang, R.H.L.: BUSINESS INTELLIGENCE AND ANALYTICS: FROM BIG DATA TO BIG IMPACT. MIS Q. 36, 1165-1188 (2012).

35. Dhar, P.V., Jarke, P.D.M., Laartz, D.J.: Big Data. Bus. Inf. Syst. Eng. 257-259 (2014)

36. Zhao, X.I.A., Xue, L.: Competitive Target Advertising and Consumer Data Sharing. J. Manag. Inf. Syst. 29, 189-221 (2013).

37. Lee, D., Youngsok Bang, J.-H.A.: MANAGING CONSUMER PRIVACY CONCERNS IN PERSONALIZATION: A STRATEGIC ANALYSIS OF PRIVACY PROTECTION. MIS Q. 35, 423-444 (2011).

38. Heimbach, I., Kostyra, D.S., Hinz, O.: Marketing Automation. 57, 129-133 (2015).

39. Pavlou, P.A.: STATE OF THE INFORMATION PRIVACY LITERATURE: WHERE ARE WE NOW AND WHERE SHOULD WE GO? MIS Q. 35, 977-988 (2011).

40. Bruns, A., Neuberger, C., Stieglitz, S., Dang-Xuan, L.: Social Media Analytics: An Interdisciplinary Approach and Its Implications for Information Systems. Bus. Inf. Syst. Eng. 89-96 (2014).

41. Hui, K.-L., Tan, B.C.Y., Goh, C.-Y.: Online Information Disclosure: Motivators and Measurements. ACM Trans. Internet Technol. 6, 415-441 (2006).

42. Rosen, P., Sherman, P.: Hedonic Information Systems: Acceptance of Social Networking Websites, Paper 162. In: Americas Conference on Information Systems. , Acapulco, Mexico (2006). 